\title{
Review of Underground Storage Tank Condition Monitoring Techniques
}

\author{
Ching Sheng Ooi ${ }^{1, *}$, Wai Keng Ngui ${ }^{2}$, Kar Hoou Hui ${ }^{1}$, , Meng Hee Lim $^{1}$ and Mohd. Salman Leong ${ }^{1}$ \\ ${ }^{1}$ Institute of Noise and Vibration, Universiti Teknologi Malaysia, Kuala Lumpur, Malaysia \\ Faculty of Mechanical Engineering, Universiti Malaysia Pahang, Malaysia
}

\begin{abstract}
This article aims to provide a comprehensive review on the condition monitoring techniques of underground storage tanks (UST). Generally, the UST has long been a favourite toxic substance reservation apparatus, thanks to its large capacity and minimum floor space requirement. Recently, attention has been drawn to the safety risks of the complex cylindrical-shaped system and its surrounding environment due to contamination resulting from unwanted subsurface leakage. Studies on related countermeasures shows that numerous efforts have been focused on the damage remediation process and fault detection practice; however, it has also been observed that there are uncertainties in present technical complications involving the effectiveness of corrective actions and the robustness of condition monitoring techniques. As an alternative means to deliver spatial information on structural integrity, the feasibility of integrating nondestructive evaluation (NDE) techniques with machine learning algorithms, on observing the degradation process of UST, so as to enhance condition monitoring competency, is discussed.
\end{abstract}

\section{Introduction}

Energy supply plays a crucial role by ensuring consumption sufficiency of a device over time to sustain an industry activity without disruption. Ranging from non-renewable coal, liquid fuel for transportation vehicles, to natural cooking gas, energy sources are categorized as hazardous substances, with flammability, corrosiveness, and chemical reactivity amongst the common traits. The mentioned toxic characteristics are also applied to industrial by-product such as radioactive waste and carbon dioxide $\left(\mathrm{CO}_{2}\right)$ [1]. Therefore, strict material-handling management and operation monitoring assessment are usually employed to prevent waste leakage, which would further evolve into undesirable intolerant faults, performance underachievement, environmental pollution and periods of downtime.

Underground storage tanks (UST) have been widely accepted for spacious energy supply reserves, refuelling and waste containments purposes. Typically found underneath petrol stations, laundry outlets and local households, the complex cylindrical-shaped containers are inevitably expose to contamination, corrosion and erosion during service periods [2-5]. Usually, the aforementioned deterioration signs focus on riskbounded areas, including welding joints, tank bottoms, manholes, pumps and piping systems as displayed in Fig. 1 [6,7]; this deterioration arises due to harsh operating surroundings, metal and liquid reactions, specific material gravity difference of liquid and tank walls, fatigue, mismanagement and fault installation [8-10].
Additionally, the underground operating nature of UST is a double-edged sword: it offers low surface area requirements but consequently induces a certain degree of monitoring difficulty. An enormous amount of research has been carried out since the norm of inspection practice such as the cathodic protection method [11] are acknowledged to be costly, labourdemanding in long term, and inadequate in providing spatial information on the state of complex UST system as a whole [12]. The study area is comprised of remediation processes and fault detection monitoring techniques targeting hazardous contents in multidisciplinary approach. Further elaboration is presented in the section UST Condition Monitoring Techniques.

Nonetheless, several unpleasant incidents including the Gulf of Mexico oil spill [13,14] and Fukushima nuclear plant leakage $[15,16]$ have recently caused legal disputes, incurring additional costs and unpredictable technical situations. Furthermore, the uncertainties in the present aging equipment risk assessment have publically raised skepticism on environment safety.

Adoption of an outdated or least rigorous condition monitoring technique at a hostile operating environment, together with heavy reliance on individual know-how and past experience amongst identified factors which contributes to undesirable events involving UST. Analysis of a total of 242 recorded UST damages lead to the conclusion that $30 \%$ of accident are preventable with quality maintenance and operations management [17]. It is believed there is rooms to improve existing

\footnotetext{
* Corresponding author: chingshengooi@gmail.com
} 


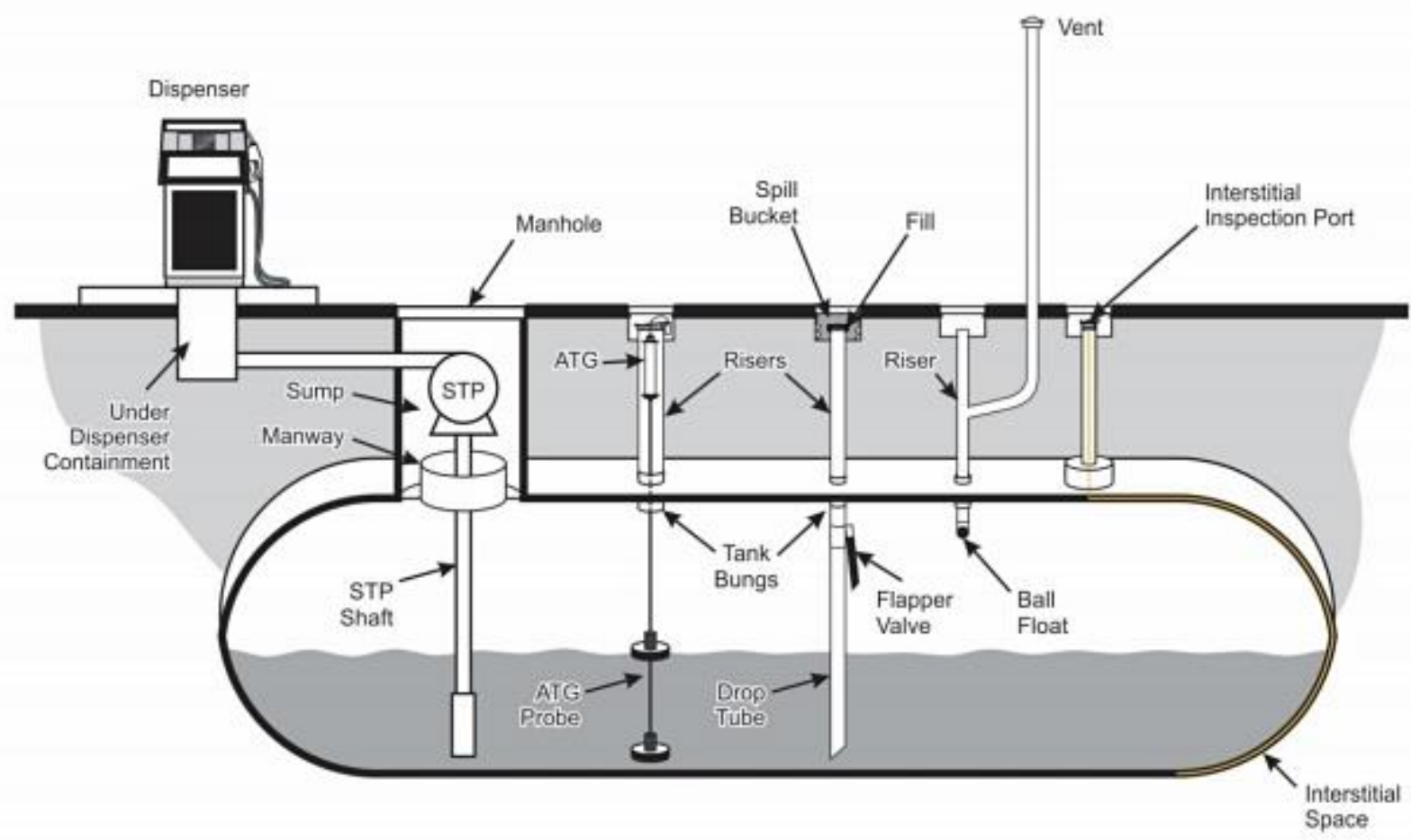

Fig. 1. General Petrol UST and Refueling Facility at Petrol Station

condition monitoring solutions for USTs after identifying the challenges and limitations. The viability of a product life cycle prediction and fault diagnosis model based on NDE techniques and machine learning algorithms will be tabulated in the Recommendations section.

\section{UST Condition Monitoring Techniques}

A variety of significant conventional monitoring techniques have been designed to cater for wide-range applications for different occasions. Notably, visual inspection performed by experienced personnel is suitable for preliminary analysis $[18,19]$. For ferrous and non-ferrous segments, oil and debris analysis is useful to detect any chips, leakage, or places where the coating may have detached [20-22]. By employing fundamental heat transfer theory, the thermography method screens structural temperature variation with respect to material properties and conductivity [23,24]. An on-line parameter tracking administration, namely Supervisory Control and Data Acquisition (SCADA) is specialized in wide coverage tribological monitoring $[25,26]$. Together with capacious data storage, SCADA's centralized control system is capable of providing an extensive review of multiple equipment or spacious facilities over time. Vibration-based analysis yet another distinctive option due to its well-established high-speed component fingerprint pattern recognition and diagnosis [27,28].

Despite proven success for the above methodologies, they are relatively inconvenient to apply to UST because of UST's restricted, difficult-to-reach underground environment characteristics. Also, due to the fact that an UST is a system influenced by multitudinal factors, straightforward conventional techniques would most likely underestimate the black box model. In addition, the low correlation between time-varying factors and relatively time-consuming filling-discharge cycle periods add to the tedious computation and slow response. Taking into account the static nature of components together with the numerous dynamic attributes of product such as the liquid volumetric flow rate, USTs are rather insensitive to motion-type monitoring. For these reasons, collective investigation into condition monitoring techniques has been performed to accommodate environmental hostility and decode the scarce available signals, both factors happening as a result of unresponsiveness from subsurface structures. The milestones and findings available in multidisciplinary studies will be described in a chronological order as below.

\subsection{UST Condition Monitoring Research Development}

Since last century, UST related condition monitoring research effort has been concentrates in several dimensions. For example, estimation of a risk-based parameter of a leaking tank was conducted by employing clean-up level approximation [29]. The transient behaviour of concentration output as described in an arbitrary-defined risk as time function is considered to be strongly subjective. A Fourier Transform infrared photacoustic spectroscopy analysis was introduced to probe UST nuclear waste [30]. In this case study, a convenient resolution on reactive waste detection with minimal hazardous pollutant handling was determined. The feasibility of utilizing commercial computational modelling methods in $\mathrm{CO}_{2}$ injection and containing process was compared under a test situation [31]. The 
capability of a list of software was discussed and improvement proposed. The Electrical Resistance Tomography (ERT) technique was deployed to conduct a UST leakage detection test [32]. To assist leakage examination, a set of evenly-distributed electrode sensor arrays generated visualization via periodic sampling of tank waste amounts.

An interdependence of temperature changes between a tank wall, its surrounding, and the liquid inside was observed during an UST temperature-control simulation using Complex Finite Fourier Transform (CFFT) [33]. The UST thermal energy regulating model also implies system response is influenced by operating conditions. An online soil-venting system was studied to remedy petrol leakage [34]. Thorough information on leakage occurrence was recorded, particularly during refuelling activity; and the cost-effectiveness of moving towards zero-emission soil is reviewed. A reusable compound, namely HDTMA (hexadecyl-trimethylammonium)kaolin was introduced as an isolation material in case of contamination [35]. The hydraulic connectivity and ability to absorb petroleum chemical possessed by HDTMA-kaolin compound is comparable with a standard bentonite mixture.

An event of UST floating roof damage was simulated by incurring liquid sloshing as a result of lengthy high seismic amplitude effects [36]. Aiming to resemble the aftermath of an earthquake, the damage prediction is enhanced by taking into account neighbouring sediments, deep basin structure and source distance of ground motion. An optic fibre mid-infrared filtering technique was applied to examine $\mathrm{CO}_{2}$ underground displacement and leakage monitoring [37]. Investigations has proven that it is practical to inspect gas admission and emission by referring to appropriate infrared characteristics: the wavelength range threshold, optical path compatibility, and optical fibre types.

An UST design review based on extreme stress analysis was carried out in the wake of a collapsed roof incident [38]. A strain gauge experimental dataset was collected under various stress tabulation settings to numerically assess the impact of structure geometry and corrosion distribution. A similar tank stress experiment has recommended weld toe geometry reinforcement in order to reduce local stresses [39]. Meanwhile, it has been observed that non-destructive Acoustic Emission (AE) signal analysis is engaged with a vertical UST floor plate scanning application [40]. The online monitoring of defects, for instance corrosion and leakage has been well-received since inactive time is no longer required.

In France, technology transfer from mining field to underground toxic gas constrained monitoring was implemented [41]. The following have proven to be efficient $\mathrm{CO}_{2}$ tracking options: a dynamic accumulation chamber located between soil and ambience for influx gas measurement; and an integrated gas sensor system gauging $\mathrm{CO}_{2}$ concentration at pit subsurface. The author emphasised that several gas parameters such as isotopic and composition influence the identification process. A type of optic fibre sensory array, namely Fibre Bragg Grating (FBG), was adopted in UST finite element model online condition monitoring [42]. The proportional relationship between strain and FBG's wavelength variation reflects tank-bottom thickness loss caused by corrosion and wall vibration response.

The Environmental Results Program (ERP) assistant tools have been proposed with the aim to reduce frequency of UST structural inspection [43]. While the plan concentrates on addressing the risk of water supply contamination, it is also found to be compliant to regulations and cost saving. Different types of tank wall material have been taken into consideration to avoid corrosion issue, for example the high tensile fibre/polymeric composite [44]; nevertheless, this substance is not suitable to develop as a tank wall material alternative due to moisture absorption. An organic palm-made insulator has demonstrated improved thermal insulation efficiency for the critical components of water tanks [45]; it could function as a thermal stress reliever under climate change stimulation.

A multidimensional membrane sensor mechanism was established to monitor gas availability, soil temperature and building composition strain parameter [46]. To provide detailed $\mathrm{CO}_{2}$ storage surveillance, the sensor measurement was validated through field application. By exploiting 3-D Coupled Euler-Lagrange (CEL) simulation, material stress and liquid sloshing height was exhibited to be inversely proportional to liquid level and height-to-radius ratio [47]. In order to optimize water tank storage design, an extensive product life cycle assessment has been performed [48]. The major environmental factors were determined to be tank and containment material, specifically, tank positioning, geometry and volume setting. Utilizing the conductive nature of petrol contaminants, the Electrical Impedance Tomography (EIT) technique was used to project underground splitting area [49]. The responses from buried electrodes are visualized via acquisition of a local projective conductivity image method.

A mobilized robot with an attached olfaction device was simulated to perform various tasks within a toxic enclosure [50]. Modelling results show that the fourwheeled device was capable of collecting samples without any movement constraints; it is convenient to investigate any chemical reaction process between interior parts of UST and its content. Spatial temperature measurement of buried enclosures has been conducted using spiral shape ultrasonic guided waves (UGW) [51]. Compared to junction-based thermocouple, the piezoelectric crystal sensors are preferred in flammability warning because they are more effective, robust and less expensive.

\subsection{Petrol and Hydrocarbons Detection Techniques}

On the other hand, prioritized consideration has been given to petrol exposure resulting from operational processes due to concerns of populous petrol stations in urban areas. Analytical evaluation suggests that release of petrol fuel in liquid-gaseous form happens during storage and transportation, together with harmful anti- 
knocking additives (benzene, lead, Methyl tertiary butyl ether (MTBE) and oxygenate) spreading into surrounding ground, water and open space. The open atmosphere measurement sampled at petrol stations indicates the existence of a high toxic mixture made up of benzene, formaldehyde, and hydrogen sulphide at a level higher than allowable limits [52]. Hence, the option of exploiting volatile hydrocarbon agent's fused passive vapour in UST defect monitoring was considered [53]. It is worth mentioning that leakage detection rate is dependent on vapour concentration in this case.

Further, the prospect of employing infused fuel oxygenate in groundwater motion tracing and gasoline contamination level was explored [54]. By referring to MTBE thermodynamic and dispersion data, the spill dissipation rate and biodeterioration of material was verified using 3-D inverse modelling. In other words, the effectiveness of remedial action on contamination was governed by the MTBE solubility rate in water source [55]. Additionally, the correlation between MTBE concentration, degradation in progress and loss of dilution charge over period was ascertained [56]. In Thailand, the volume of volatile fuel organic compounds (VFOC) at petrol station space areas were computed and visualized in an isoconcentration contour map to display the distribution of evaporated benzene and toluene [57]. As a result, a significant profile was observed at UST inlet points.

By recruiting sulphate as the electron acceptor in a groundwater treatment experiment, toluene demonstrated a maximum reduction in percentage, subsequently followed by benzene and MTBE [58]. However, the effectiveness of hydrocarbon bioremediation lessens as microbial levels become reduced over time. The soil and groundwater sample data around a petrol station was evaluated using hydrocarbon indices and principal component analysis (PCA) method to determine the effect of related operational activity on the intermidate environment [59]. Correspondingly, the pollution rate due to UST fuel leakage was correlated to VFOC and diesel range organics (DRO) readings. The prospect of utilizing a half-life dissipation model in estimating MTBE (which remains in aquifer over time) has been explored [60]. The predicted gasoline oxygenate concentration rate via first order kinetics equation matched real-time field measures; hence, it is applicable for public water supply damage severity mapping.

A novel carbon nanotube (CNT) sensor system was purposely designed with nanocomposite material to cater a violent underground surveillance [61]. The sensitivity of the aforementioned sensory mechanism is enhanced with the existence of time-varying parameters such as soil compost, humidity, pressure and temperature in output matrix. In order to deduce total release petrol hydrocarbons (TPHs) available in the vertical extent of soil, a 2-D grid view comprised of multiple plane was examined by polymerase chain reaction- denaturing gradient gel electrophoresis (PCR-DGGE) technique [62]. An analytical relationship between formations of microbial communities, leakage volume, texture and depth was defined based on field-test studies. An innovative in situ chemical oxidation (ISCO) method was acquired to investigate the progress of aqueous treatment after UST gasoline leakage effects [63]. Potassium ferrate $\left(\mathrm{K}_{2} \mathrm{FeO}_{4}\right)$ has been proven to be a more stable oxidizing agent in degrading active hydrocarbon migration elements (BTEX and MTBE) over diverse medium compositions ( $\mathrm{pH}$ and concentration), as compared to permanganate and hydrogen peroxide.

A fuel leakage phase-change model was computed with respect to UST shape and surrounding area [64]. The contained liquid-gaseous proportion was projected into low explosion limit (LEL) indication to avoid fire accidents and eventually assist in efficient periodic corrective action selection. An electrical resistivity visualization technique was unveiled to target subsurface oil pollution spots around coastal cities in India [65]. This was realized by applying a set of multi-gas sensors to identify the hydrocarbon level in soil vapour sampling. Hydrocarbon spoil treatment outcomes has been compared extensively using land farming bioremediations in Nigeria [66]. Fertilizer was proven to be the most cost effective addition, over biochar, biosurfactant and other heterogeneous nutrient agents.

\subsection{Rule and Regulation Changes}

As unpredictability in UST leakage increases, in terms of occurrence and damage severity, more stringent guiding principles in installation, operation, maintenance and safety have been proposed, amended and implemented by the authorities and professional organizations.

For example, The Environment Protection Agency (EPA) has updated a set of UST-related regulations which covers hardware reinforcement, increases the frequency of scheduled maintenance and requires the latest on-site certification for operators in charge [67]. In addition, the public has been motivated by the federal government of the United States to perform standardized monitoring practices revised by professional organizations. The imposed exemplar and guideline comprises the aspects of setting up, structural integrity assessment and health monitoring, operation and fulfilment activities, fault detection, corrosion protection methods and other general subjects.

Meanwhile, renowned industry manufacturer The Welding Institute (TWI) in the UK has implemented a wall thickness measurement criterion for pressure vessel product suggested by American Petroleum Institute (API) [68]: operating instructions for apparatuses in an ignitable environment [69]; and a reformed guideline for degrading steel products respective to the working environment [70]. Domestic standard regulations for USTs in Malaysia include: liquid storage steel tanks design specification [71]; an international guideline for welding procedures [72]; and an accredited welding technical qualification specifically for steel fusion [73].

Clearly, a series of proactive moves toward tightening up regulation lists serve as countermeasures in preventing and minimizing contamination problems, particularly against aging UST products. However, the 
UST-associated guidelines mentioned above cover a wide area and has been revised in a periodic manner to be flexible according to modern technology trends and multiple regions; thus, it is recommended to comply when applicable.

\section{Challenges and Limitations}

To summarize, it can be deduced that substantial research with the aim to upgrade the UST condition monitoring model has been conducted. More specifically, the vast efforts incurred range from property extraction of tracking additives, auxiliary sensors, simulation modelling, product material research and design modification, process control, enforcement of a stricter standard compliance, multivariate statistical analyses, to matured technology transfer from proven case studies (Fig. 2). Evidently, the applications require a coherent collective field of knowledge with respect to the diverse physical form of contained material (Fig. 3), in order to overcome identified shortcomings in delivering sensitive inspection of USTs.

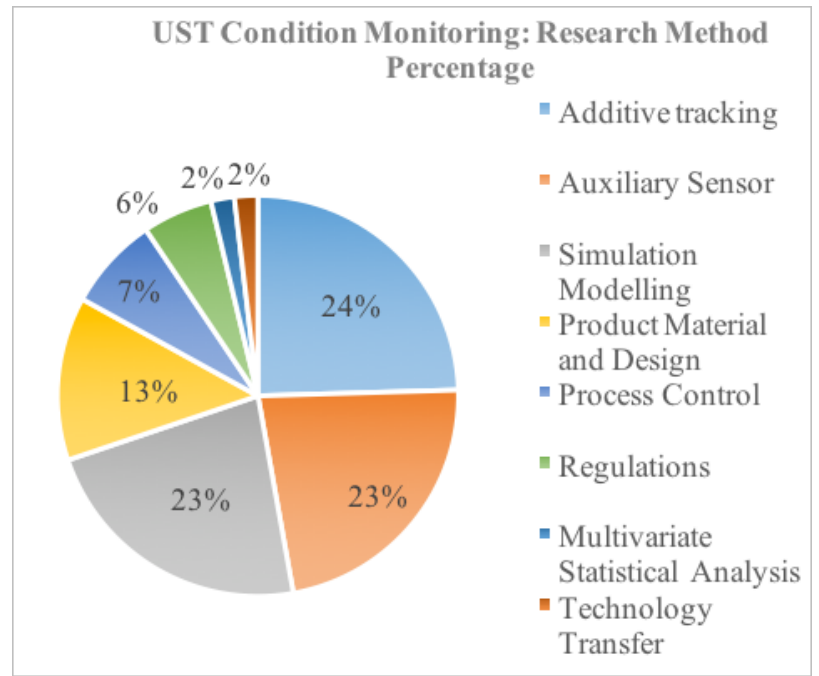

Fig. 2. UST Condition Monitoring Research Method Percentage

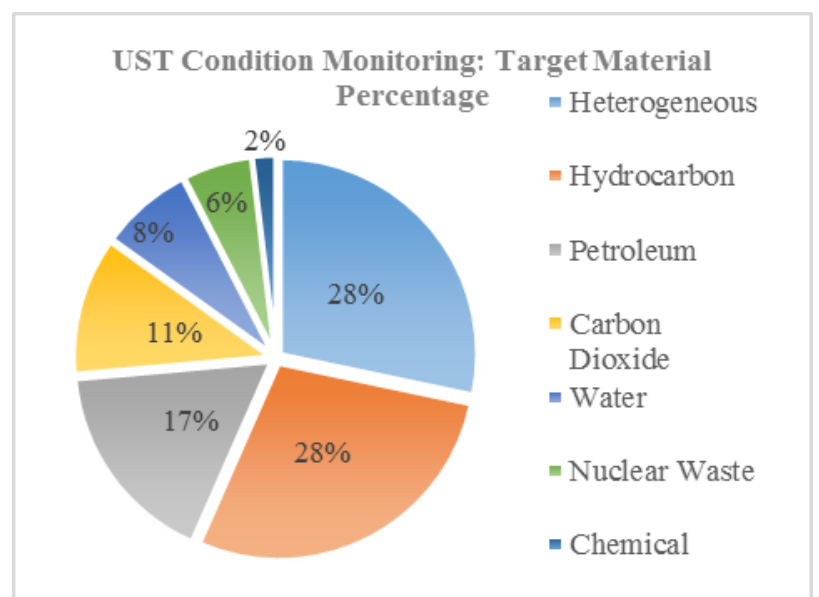

Fig. 3. UST Condition Monitoring Target Material Percentage

Nonetheless, obviously the present research direction has an emphasis on contaminant remedial action and leakage detection (Figure 4). While remedy effectiveness remains in question, fault detection capability means that the condition monitoring process is capped at lower levels one and two [74,75]. Without the ability to perform fault severity calibration and predict a product's lifespan, there remains insufficient information provided to understand the situation behind prior leakage, and it is too late if the damage is done. Furthermore, this statement is confirmed by the numerous health issues reported on petrol station assistants [57]; pollution prevention strategies opt for better cost-saving, energy conservation and health care measures [76] after a thorough hydrocarbon leakage evaluation.

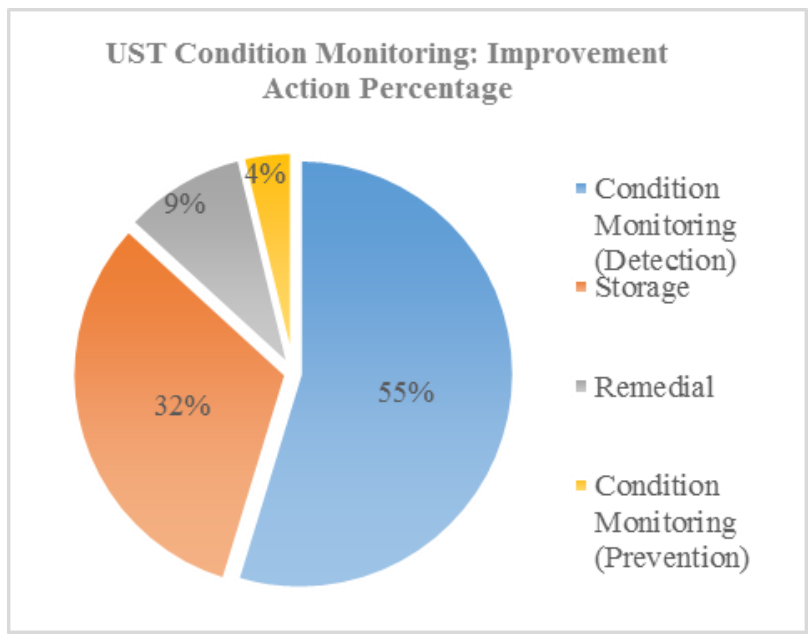

Fig. 4. UST Condition Monitoring Improvement Action Percentage

Review on vibration structural health monitoring [77] encourages the exploration of signal response to utilize its fundamental statistical pattern recognition in developing advanced model- or non-model-based system identification. Analogous to vibration, a non-destructive evaluation (NDE) signal responds in an identical manner: the amplitude of waveform energy reflects the existence of abnormal events. Typically, statistical analysis is compatible with waveform interpretation due to its attribute's simplicity. However, it is observed that the trade-off relationship between the complexity of condition monitoring model and its accuracy are nontrivial. In general, simulation modelling supported by a combination of detailed theoretical background and mathematical settings will generate more precise performance, but it is computationally tedious. On the contrary, a plain, direct model could face a bottleneck when analysing complicated situation such as simultaneous monitoring and weighting of abundant signals. Comparatively, outlier detection can be achieved by extracting fundamental vibration features and applying it to techniques such as statistical process control (SPC) [78], adaptive template matching (ATM) [79], wavelet transform (WT) [80], or Fourier Transform [81], but the aforementioned methods are far away from mimicking reality and demand human supervision.

Based on the above reasoning, the following research concentrates on the necessity and fulfilment of machine learning algorithms by making use of NDE signal- 
extracted features. By means of gaining sharp and retentive pattern-recognition memory, improvement is anticipated for the condition monitoring ability by developing a multi-fault classification model for USTs, labelling the severity scale and predicting the lifecycle of the product altogether.

\section{Recommendation}

\subsection{Availability of NDE and its Advantages}

As mentioned in the previous section, several NDE techniques have been inquired to address drawbacks introduced by the current trend. NDE is favourable since it possesses numerous advantages over conventional practice in identifying structural integrity over time. Similar to $\mathrm{x}$-ray scanning in the medical sector, NDE signals are intended to detect an anomaly and pinpoint its position within the effective scanning area, with unlimited number of testing trials. Interpretation of encoded NDE signals is always paramount, though laborious. Hence, practising suitable NDE techniques for a unique case study is essential in pursuance of potential ability, and it can be reflected from multiple factors: parameter setting, sensitivity, adaptability, compatibility, and ease of implementation. Because of the considerable numbers in the NDE list, only choices that fits the required criteria on paper will be discussed, including ultrasonic guided wave (UGW) and acoustic emission (AE).

Ultrasonic guided wave technique is a branch of ultrasonic testing (UT) which release low frequency sound energy $(50 \mathrm{kHz}-200 \mathrm{kHz})$ mainly for cylindrical shape cross sectional and material characterization inspection purposes $[82,83]$ and it has been extended to other complex shapes $[84,85]$. It is expert in long distance inspection owing to the capability of an induced stress wave to travel along the specimen's boundary. Since it is an active pulse/echo method, the pulse emitter and receiver of an UGW are typically attached to a material surface alongside each other; waveform signals created by a set of electronic pulse-driven transducers embeds into specimen and propagates in perpendicular directions.

When UGW eventually encounters discontinuity such as circumference variation, material properties and grains difference, propagating energy is reflected. The reflecting amplitude (A-scan) and shape (C-scan) express the extent of dissimilarities in size and orientation respectively; while the location of the reflector is measured from either frequency signal or time of flight (TOF). Nevertheless, the proficiency of UGW is slightly hindered by its own nature. Researchers has been aiming to overcome gaps concerning UGW's signal intensity, which diminishes after endured severe travel distance due to attenuation activities [86,87]; and its insensitivity to axial anomaly, which appears to be coincide with the travel direction of signal [88].

Contrary to any other common NDE techniques, acoustic emission is well-known as a passive approach since it anticipates signal waves produced by specimens themselves, instead of putting effort into creating energy for feedback $[89,90]$. Fundamentally, under continuous, repetitive stress conditions (tensile, compressive, shear, bending and torsion), the mechanical properties of a specimen will experience alteration over time and breakdown when the force applied exceeds the sustainable limit. When failings such as deformation and fatigue arise, AE-encoding sensors concentrate on converting high-frequency acoustic stress waves (15 $\mathrm{kHz}-300 \mathrm{kHz}$ ) as a result of local loaded elastic kinetic energy discharge by discontinuities, into amplified electronic signals. The preliminary $\mathrm{AE}$ waveform proportionally describes the size and speed of defects; with the help from initiative data processing, it is suitable to monitor changes of a mechanical loaded structure, locate and identify incurred damages. Secondary forces such as friction, which interfere in the signal-to-noise (SNR) ratio remain a doubt in $\mathrm{AE}$ implementation [91].

It is of profound importance to recognize that UGW and $\mathrm{AE}$ holds different characteristics yet are superior in their own ways. It has been observed that UGW is indicated in elongated inspection areas, complex shapes and uncompromising environments [92-96], while AE is more suited to dynamic and mechanical applications [97102]. That being said, practicing the above-mentioned NDE technique solely in UST monitoring is foreseen to be problematic due to individual distinctive features. For $\mathrm{AE}$ alone, inconsistency of mechanical stress applied on different UST body segments could lead to neglect of the upper segment, while UGW could overlook laminations and porosities, as well as uniform corrosion and erosion when considering negligible cross-sectional differences in range.

For better evaluation efficiency, the signal fusion approach has been offered in the interest of a diverse interpretation perspective $[103,104]$. For USTs in particular, the signal fusion concept suggests that both $\mathrm{AE}$ and UGW signals be emitted from adjacent directions, merging to forge a mesh-like screening field in favour of blind spot minimization. Besides, it is obvious that raw NDE signals require comprehensive numerical review with regards to identifying anomalies symptoms of anomalies and elimination of false alarms in automated mode [105].

\subsection{UST Condition Monitoring Model Package}

The NDE signal plays a vital role as input signal in the UST model evaluation which could be separated into three main intermediates: material screening, signal processing and machine learning fault classification (Figure 5). With UST as the target, NDE signals react to stress-strain tabulation, cross sectional dissimilarity, liquid level contents and the amount of tank bottom settlement during material screening process without injuring the product structure.

The raw signals obtained from respective sensors mounted at appropriate locations carry little meaning without diagnosis from relevant signal processing algorithms. By applying noise reduction, feature 


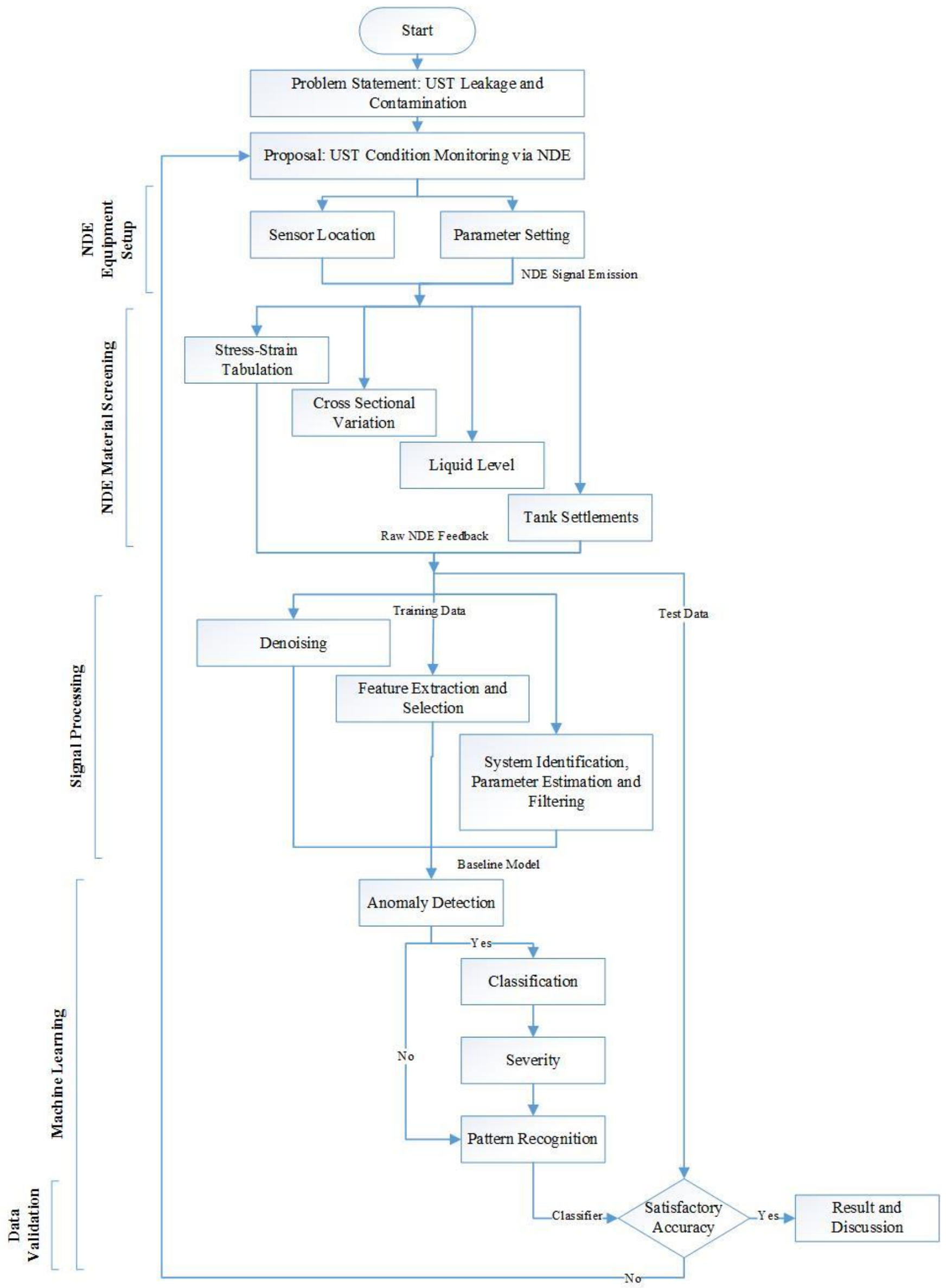

Fig. 5. Proposed UST Condition Monitoring Flow Chart 
extraction, system identification, parameter estimation and filtering methods [106,107], the aim is to increase the SNR ratio and form a baseline mathematical equation to determine the relationship between signal response and product properties under various states. Other benefits consist of establishing strategic sensor placement to avoid bulky instruments and degraded performance caused by overfitting [108]; this reduces uncertainties, and provides an overview on both UST black box characteristics and cost optimization.

Next, machine learning algorithms will be responsible for analysing the processed signal distribution representing the linear characteristic of extracted features via the pattern recognition mechanism [109]. By means of analytical and numerical reasoning, a machine learning algorithm tends to detect and memorize deviations as anomalous, classify anomaly type according to outlier properties and determine the degree of severity of a given state of affairs through baseline model comparison. The fitness of the supervised classifier will be appraised by testing the dataset revealed after training stage, using multi-fold crossvalidation to avoid bias [110]. The best performer with least forecast error will be obtained as predictor in integrated condition monitoring model.

Practically, a predicting model functions under the influence of uncertainties appearing in the form of measurement noise, quality of extracted features and model design [111]. Future trends of machine learning lie in artificial intelligence (AI) agents cascaded with automated optimization or probabilistic functions. Numerous case study implies that AI's use has been rewarding in NDE signal classification and prediction in terms of accuracy, sensitivity and automated system, with recursive Artificial Neural Network (ANN) [112], wavelet based Support Vector Machine (SVM) [113], Euclidean-SVM [114], Bayesian Belief Network trained 'statistical-physical' and 'hypothesis-generating' model [115], wavelet decomposition- continuous hidden markov model (CHMM) integration [116] amongst modern proposed techniques. Though it already displays an outstanding yield, the AI classifier can still be improved by incorporating uncertain variables into

\section{References}

1. S.L. Bryant, The one-stop carbon solution an ingenious plan would bury carbon while providing fuel for electricity, Scientific American 309, 72-77 (2013)

2. L. Popoola, et al., Corrosion problems during oil and gas production and its mitigation, International Journal of Industrial Chemistry 4 (35) (2013)

3. J.W. Sowards, E. Mansfield, Corrosion of copper and steel alloys in a simulated underground storage-tank sump environment containing acidproducing bacteria, Corrosion Science 87, 460-471 (2014) deterministic model using stochastic estimation [117119].

\section{Conclusion}

With the motivation to reduce the occasions of distasteful containment leakage, pollution and corrective action, a significant amount of review has been discussed with the motivation to reform the UST condition monitoring model. In response to needs, the NDE technique is considered to be a competitive option amongst condition monitoring techniques in terms of sensitivity, cost-effectiveness and ease of installation. In addition, the hypothetically UGW-AE signal fusion seems to be more promising compared to a single signal emission in delivering spatial information of an UST as a whole, while coordinating with difficult operating surroundings and product shape complexity. Furthermore, signal processing and machine learning algorithms are integrated into the condition monitoring model as tools to interpret the retrieved NDE input signal, and perform automated pattern recognition fault classification if any outlier is located.

However, the study was conducted based on theory and experience from different applications, thus implementation on actual UST is foreseen to be effortful and challenging. This includes but is not limited to determining the location of sensors, establishing coherence between a pair of NDE signals and algorithm, SNR, signal feature extraction and selection, separation of genuine faults and false alarms, and classifier accuracy.

\section{Acknowledgement}

This study is sponsored by Institute of Noise and Vibration UTM under the Higher Institution Centre of Excellence (HICoE) Grant Scheme (R.K130000.7809.4J225, R.K130000.7809.4J226, R.K130000.7809.4J227 \& R.K130000.7809.4J228). Additionally, the main author also supported by the UTM Research University Grant (Q.K130000.2543.11H36) for his Ph.D. study.

4. R.B. Rebak, Materials in nuclear waste disposition, Jom 66, 455-460 (2014)

5. C.H.D. Williamson, et al., Microbially influenced corrosion communities associated with fuel-grade ethanol environments, Applied Microbiology and Biotechnology 99, 6945-6957 (2015)

6. United States Environment Protection Agency (EPA), Preventing and detecting underground storage tank (UST) release (2015) Available: https://www.epa.gov/ust/preventing-and-detectingunderground-storage-tank-ust-releases

7. B. DuBose, EPA finds moderate or severe corrosion in most underground diesel tanks (2016) Available: https://www.materialsperformance.com/articles/mat erial/selectiondesign/2016/09/epa-finds-moderate- 
or-severe-corrosion-in-most-underground-diesel$\underline{\text { tanks }}$

8. R. Kazys, R. Sanderson, Condition monitoring of large oil and chemical storage tanks using guided waves, BINDT annual Conference, Torquay, UK (2004) Available: http://www.twiglobal.com/technical-knowledge/publishedpapers/condition-monitoring-of-large-oil-andchemical-storage-tanks-using-guided-wavesseptember-2004/.

9. Á, Angulo, S. Soua, Long range ultrasonic guided waves for pipeline inspection, COMSOL conference, Cambridge, UK (2014)

10. J. Kanfoud, et al., New reliable technology for soil inspection using active vibration control in contaminated sites with drilling machinery condition monitoring, CM \& MFPT, 1-13 (2015)

11. Evironment Protection Agency (EPA), Release detection for underground storage tanks and piping: Straight talk on tanks (2016) Available: https://www.epa.gov/ust/release-detectionunderground-storage-tanks-and-piping-straighttalk$\underline{\text { tanks }}$

12. K. Damen, et al., Health, safety and environmental risks of underground $\mathrm{CO}_{2}$ storage overview of mechanisms and current knowledge, Climate Change 74, 289-318 (2006)

13. D.R. Petrolia, What have we learned from the deepwater horizon disaster? an economist perspective, Journal of Ocean and Coastal Economics 2014 (2015)

14. E. Buskey, et al., Impact of oil spills on marine life in the gulf of Mexico: Effect on plankton, nekton and deep-sea benthos, Oceanography 29, 174-181 (2016)

15. P.P. Povinec and K. Hirose, Fukushima radionuclides in the $N W$ Pacific, and assessment of doses for Japanese and world population from ingestion of seafood, Sci. Rep. 5 (9016) (2015)

16. A.H. Gallardo and A. Marui, The aftermath of the Fukushima nuclear accident: Measures to contain groundwater contamination, Science of the Total Environment 547, 261-268 (2016)

17. J.I. Chang, C.-C. Lin, A study of storage tank accidents, Journal of Loss Prevention in the Process Industries 19, 51-59 (2006)

18. M. Burdumy, et al., One-second MRI of a threedimension vocal tract to measure dynamic articulator modifications, Journal of Magnetic Resonance Imaging 46, 94-101 (2016)

19. J.G. Chen, et al., Video camera-based vibration measurement for civil infrastructure applications, Journal of Infrastructure Systems 23 (2017)

20. J. Poley, M. Dines, Metallic wear debris sensors : promising developments in failure prevention for wind turbines gearsets and similar components, Industrial and Commercial Applications of Smart Structures Technologies (2011)
21. S. Lunt, et al., Recent developments in online oil condition monitoring sensors and alignment with ASTM methods and practices, Journal od ASTM International 8 (103632) (2011)

22. X. Yan, et al., Study of on-line condition monitoring and fault feature extraction for marine diesel engines based on tribological information, Proceedings of the Institution of Mechanical Engineers, Part O : Journal of Risk and Reliability 229, 291-300 (2014)

23. B. Yuan, et al., Eddy current thermography imaging for condition-based maintenance of overlay welded components under multi-degradation, Marine Structures 53, 136-147 (2017)

24. B.S. Prasad, et al., Condition Monitoring of tuning process using infrared thermography technique : an experimental approach, Infrared Physics \& Technology 81, 137-147 (2017)

25. J. Dai. et al., Power fluctuation evaluation of largescale wind turbine based on SCADA data, IET Renewable Power Generation 11, 395-402 (2017)

26. J. Tautz-Weinert, S.J. Watson, Using SCADA data for wind turbine condition monitoring: a review, IET Renewable Power Generation 11, 382-394 (2017)

27. C. Faure, et al., Empirical and fully bayesian approaches for the identification of vibration sources from transverse displacement measurements, Mechanical System and Signal Processing 94, 180-201 (2017)

28. W. Zhang, et al., Vibration response analysis of an elastic-support cantilever beam with crack and offset boundary, Mechnaical System and Signal Processing 95, 205-218 (2017)

29. K. Evans and P. Bedient, A transient methodology fo assessing risk: Development and comparison with the conventional approach, The Proceedings of the 1995 Petroleum Hydrocarbons and Organic Chemicals in Ground Water : Prevention, Detection, and Remediation. Conference and Exposition, Houston, Texas, 111-125 (1995)

30. S. Bajic, et al., Analysis of underground storage tank waste simulants by fourier transform infrared photoacoustic spectroscopy, Applied Spectroscopy 49, 1000-1005 (1995)

31. L.V.D. Meer, Computer modelling of underground $\mathrm{CO}_{2}$ storage, Energy Conversion and Management 37, 1155-1160 (1996)

32. W. Daily, Electrical resistance tomography, The Leading Edge (2004)

33. R Yumrutaş, et al., Computational model for a ground coupled space cooling system with an underground energy storage tank, Energy and Buildings 37, 353-360 (2005)

34. R. Sacile, Remote real-time monitoring and control of contamination in underground storage tank systems of petrol products, Journal of Cleaner Production 15 (13-14), 1295-1301 (2007) 
35. C.-H. Moon, et al., Organically modified low-grade kaolin as a secondary containment material for underground storage tanks, Environmental Geochemistry and Health 29, 271-280 (2007)

36. K. Hatayama, Lessons from the 2003 Tokachi-Oki, Japan, earthquake for prediction of long-period, Journal of Seismology 12, 255-263 (2007)

37. F. Charpentier, et al., Infrared monitoring underground $\mathrm{CO}_{2}$ storage using chalcogenide glass fiber, Optical Materials 31 (3), 496-500 (2009)

38. F. Trebuňa, et al., Failure analysis of storage tank, Engineering Failure Analysis 16 (26-38) (2009)

39. J.-S. Kim, et al., A failure analysis of fillet joint cracking in an oil, Journal of Loss Prevention in the Process Industries 22, 845-849 (2009)

40. L. Sun, Y. Li, Large vertical storage tank bottom evaluation via acoustic emission signal analysis, Control and Decision Conference (CCDC), Chinese IEEE, Mianyang, China (2011)

41. S.C.A. Lafortune, et al., First steps in coupling continous carbon isotopic measurements with already proven subsurface gas monitoring methods above underground carbon dioxide storage sites, Energy Procedia 4, 3526-3533 (2011)

42. G.I. Sarkandi, A Zabihollah, A computational model for health monitoring of storage tanks using fiber bragg grating optical fiber, Journal of Civil Structural Health Monitoring 1, 97-102 (2011)

43. R.T. Enander, et al., Reducing drinking water supply chemical contamination: Risks from underground, Risk analysis 32, 2182-2197 (2012)

44. B. Yousif, H. Ku, Suitability of using coir fiber/ploymer composite for the design of liquid storage, Material \& Design 36, 847-853 (2012)

45. H. Fouli, Assessing the efficiency of palm-based insulators for storage water tanks under variable ambient temperatures, Arabian Journal for Science and Engineering 38, 1321-1332 (2013)

46. M. Bartholmai, et al., Multifunctional sensor for monitoring of $\mathrm{CO}_{2}$ underground storage by comprehensive and spatially resolved measuring of gas concentrations, temperature and structure changes, Energy Procedia 37, 4033-4040 (2013)

47. V. Mittal, et al., Dynamic analysis of liquid storage tank under blast using coupled eulerlagrange formulation, Thin-Walled Structures 84, 91-111 (2014)

48. D. Sanjuan-Delmás, et al., Environmental and geometric optimisation of cylindrical drinking water storage tanks, The Internatiobal Journal of Life Cycle Assessment 20, 1612-1624 (2014)

49. M.-E., Ts, et al., Remote real time monitoring for underground contamination in Mongolia using electrical impedance tomography, Journal of Nondestructive 35 (2015)

50. A.A. Razak, et al., Mobile robot structure design, modelling and simulation for confined space, $2^{\text {nd }}$
IEEE International Symposium on Robotics and Manufacturing Automation (ROMA), IEEE (2016)

51. S. Periyannan, K. Balasubramaniam, Distributed temperature sensing using a spiral configuration, AIP Conference Proceedings 1806(1) (2016)

52. G.P. Macey, et al., Air concentrations of volatile compounds near oil and gas production: a community based, Environmental Health 13 (2014)

53. D. Weber, F. Schwille, Passive vapor monitoring of underground storage tanks for leak detection, Environmental Monitoring and Assessment 16, 99116 (199)

54. G.A. Robbins, et al., Occurrence of MTBE in heating oil and diesel fuel in Connecticut, Ground Water Monitoring and Remediation 20, 82-86 (2000)

55. J. Wilson, et al., Monitored natural attenuation of MTBE as a risk management option at leaking undergroud storage tank sites, Environmental Protection Agency (2005) Available : https://nepis.epa.gov/Exe/ZyPDF.cgi/2001716R.PD F?Dockey=20017I6R.PDF

56. A.E. Kehew, P.M. Lynch, Concentration trends and water-level fluctuations at underground storage tank sites, Environmental Earth Sciences 62, 985998 (2010)

57. T. Sairat, et al., Investigation of gasoline distributions within petrol stations: sptial and seasonal concentrations, sources, mitigation measures, and occupationally exposed symptoms, Environmental Science and Pollution Research 22, 13870-13880 (2015)

58. W.H. Huang, C.M. Kao, Bioremediation of petroleum-hydrocarbon contaminated groundwater under sulfate-reducing conditions: Effectiveness and mechanism study, Journal of Environmental Engineering 142(3) (2016)

59. M. Balseiro-Romero, et al., Characterization and fingerprinting of soil and groundwater contamination sources around a fuel distribution station in Galicia (NW Spain), Environmental Monitoring and Assessment 188 (2016)

60. M.J. Metcalf, et al., Application of first order kinetics to characterize MTBE natural attenuation in groundwater, Journal of Contaminant Hydrology 187, 47-54 (2016)

61. K. Parmar, et al., Robust direct hydrocarbon sensor based on novel carbon nanotube nanocomposites for leakage detection, 11th International Pipeline Conference: Operations, Monitoring and Maintenance ; Material and Joining. Vol. 3. Pipeline Division, ASME, Calgary, Alberta, Canada (2016)

62. M. Andreolli, et al., Bioremediation of diesel contamination at an underground storage tank site: a spatial analysis of the microbial community, World Journal of Microbiology and Biotechnology 32 (2015) 
63. R.C.P. Minetti, et al., In situ chemical oxidation of btex and mtbe by ferrate: ph dependence and stability, Journal of Hazardous Materials 324, 448456 (2017)

64. B. He, et al., A numerical simulation study on the formation and dispersion of flammable vapor cloud in underground confined space, Process Safety and Environmental Protection 107, 1-11 (2017)

65. I.M. Nambi, et al., An assessment of subsurface contamination of an urban coastal aquifer due to oil spill, Environmental Monitoring and Assessment 189, (2017)

66. D.M. Brown, et al., Comparison of landfarming amendments to improve bioremediation of petroleum hydrocarbons in niger delta soils, Science of The Total Environment 596-597, 284292 (2017)

67. United States Environmental Protection Agency (EPA), Revising underground storage tank regulations - revisions to existing requirements and new requirements for secondary containment and operator training; final rule (2017) Available: https://www.epa.gov/ust/revising-undergroundstorage-tank-regulations-revisions-existingrequirements-and-new

68. American Petroleum Institute (API), Pressure Vessel Inspection Code: In-Service Inspection, Rating, Repair, and Alteration (API 510) (2017)

69. European Commission, Guidelines: Equipment and protective systems intended for use in potentially explosive atmospheres, (ATEX 2014/34/EU), Brussels, Belgium (2016)

70. ASTM International, Standard Test Methods and Definitions for Mechanical Testing of Steel Products, (ASTM A370-17), West Conshohocken, PA (2017)

71. British Standards Institute (BSI), Specification for the design and manufacture of site built, vertical, cylindrical, flat-bottomed, above ground, welded, steel tanks for the storage of liquids at ambient temperature and above (AMD Corrigendum 15597), (BS EN 14015:2004), London, UK (2004)

72. The International Organization for Standardization (ISO), Specification and qualification of welding procedures for metallic materials Welding procedure test Part 1: Arc and gas welding of steels and arc welding of nickel and nickel alloys, (ISO 15614-1:2017), , Berlin, Germany (2017)

73. The International Organization for Standardization (ISO), Qualification testing of welders - Fusion welding, (ISO 9606-1:2012), Berlin, Germany (2012)

74. A. Rytter, Vibrational based inspection of civil engineering structures, Ph.D. thesis, Dept. of Building Technology and Structural Engineering, Aalborg University (1993)
75. E.P. Carden, Vibration based condition monitoring: A review, Structural Health Monitoring 3, 355-377 (2004)

76. M. Hillpert, et al., Hydrocarbon release during fuel storage and transfer at gas stations: Environmental and health effects, Current Environmental Health Reports 2, 412-422 (2015)

77. C.R. Farrar, S.W. Doebling, Damage detection and evaluation II, Modal Analysis and Testing, 363, Springer, Dordrecht (1999)

78. A.B.A. Dawod, et al., On model selection for autocorrelated processes in statistical process control, Quality and Reliability Engineering International 33, 867-882 (2016)

79. Z. Li, et al., Robust object tracking based on adaptive templates matching via the fusion of multiple features, Journal of Visual Communication and Image Representation 44, 1-20 (2017)

80. Y. Jung, H. Kim, Detection of pvc by using a wavelet-based statistical ecg monitoring procedure, Biomedical Signal Processing and Control 36, 176182 (2017)

81. W.K. Ngui, et al., Blade fault diagnosis using artificial neural network, International Journal of Applied Engineering Research 12(4), 519-526 (2017)

82. V. K. Chillara, C. J. Lissenden, Review of nonlinear ultrasonic guided wave nondestructive evaluation: theory, numerics, and experiments, Optical Engineering 55 (1) (2015)

83. M. Eybpoosh, et al., Effects of damage location and size on sparse representation of guided-waves for damage diagnosis of pipelines under varying temperature, Structural Health Monitoring and Inspection of Advanced Materials, Aerospace, and Civil Infrastructure (2015)

84. J. Cheng, L.J. Bond, Assessment of ultrasonic NDT methods for high speed rail inspection, AIP Conference Proceedings, 1650 (1) (2015)

85. N.K. Mutlib, et al., Ultrasonic health monitoring in structural engineering: buildings and bridges, Structural Control and Health Monitoring 23, 409422 (2015)

86. P. Wilcox, et al., The effect of dispersion on longrange inspection using ultrasonic guided waves, NDT \& E International 34, 1-9 (2001)

87. E. Leinov, et al., "Guided wave attenuation in pipes buried in sand," Journal of Sound and Vibration 347, 96-114, 2015

88. Z. Zhang, et al., The influence of different slopes of defects on ultrasonic guided-wave in flat steel, Advanced Research and Technology in Industry Applications (WARTIA), IEEE Workshop. IEEE, Ottawa, ON, Canada, 47-49 (2014)

89. A.A. Pollock, Inspecting Bridge with Acoustic Emission, Guidelines prepared for the U.S. Department of Transportation and Federal Highway Administration (FHWA), Technical Report TR-103- 
126/95, Physical Acoustic Corp., Princeton Junction, NJ (1995)

90. K.M. Holford, et al., A new methodology for automating acoustic emission detection of metallic fatigue fractures in highly demanding aerospace environments: An overview, Progress in Aerospace Sciences 90, 1-11 (2017)

91. J. Walsh, et al., Monitoring the condition of marine renewable energy devices through underwater acoustic emissions: Case study of a wave energy converter in Falmouth Bay, UK, Renewable Energy 102, 205-213 (2017)

92. R. Raišutis, et al., Ultrasonic guided wave-based testing technique for inspection of multi-wire rope structures, NDT \& E International 62, 40-49 (2014)

93. M.K. Yücel, et al., An ultrasonic guided wave approach for the inspection of overhead transmission line cables, Applied Acoustics 122, 23-34 (2017)

94. S. Sharma, A. Mukherjee, Ultrasonic guided waves for monitoring the setting process of concretes with varying workabilities, Construction and Building Materials 72, 358-366 (2014)

95. B. Masserey, et al., High-frequency guided ultrasonic waves for hidden defect detection in multi-layered aircraft structures, Ultrasonics 54, $1720-1728$ (2014)

96. O.M. Malinowski, Ultrasonic guided wave testing of finned tubing, ASME Pressure Vessels and Piping Conference: High-Pressure Technology; Rudy Scavuzzo Student Paper Competition and 23rd Annual Student Paper Competition; ASME NDE Division. Vol. 5. Pressure Vessels and Piping Division, ASME, Boston, Massachusetts, USA (2015)

97. C. Beggan, et al., Using acoustic emission to predict surface quality, The International Journal of Advanced Manufacturing Technology 15, 737- 742 (1999)

98. K. Asamene, M. Sundaresan, Acoustic emissionbased monitoring of surfaces subjected to friction, Nondestructive Characterization for Composite Materials, Aerospace Engineering, Civil Infrastructure, and Homeland Security. Proc. SPIE (2012)

99. S. Shahidan, et al., Damage classification in reinforced concrete beam by acoustic emission signal analysis, Construction and Building Materials 45, 78-86 (2013)

100.R. Ernst, et al., One sensor acoustic emission localization in plates, Ultrasonics 64, 139-150 (2016)

101.A.H. Muntakim, et al., Interpretation of acoustic field data for leak detection in ductile iron and copper water-distribution pipes, Journal of Pipeline Systems Engineering and Practice 8 (3) (2017)

102.B. Dykas, J. Harris, Acoustic emission characteristics of a single cylinder diesel generator at various loads and with a failing injector, Mechanical Systems and Signal Processing 93, 397414 (2017)

103.M.K. Lim, H. Cao, Combining multiple NDT methods to improve testing effectiveness, Construction and Building Materials 38, 1310-1315 (2013)

104.M. Liu, et al., Applications of a nanocompositeinspired in-situ broad- band ultrasonic sensor to acousto-ultrasonics-based passive and active structural health monitoring, Ultrasonics 78, 166174 (2017)

105.T. Parthipan, et al., Long range ultrasonic inspection of aircraft wiring, 23rd International Symposium on Industrial Electronics (ISIE), IEEE, Istanbul, Turkey (2014)

106.M. Grewal, A. Andrews, Applications of kalman filtering in aerospace 1960 to the present [historical perspectives], IEEE Control Systems Magazine 30, 69-78 (2010)

107.S. Cuentas, et al., Support vector machine in statistical process monitoring: a methodological and analytical review, The International Journal of Advanced Manufacturing Technology 91, 2016

108.J.-G. Lee, et al., Deep learning in medical imaging: General overview, Korean Journal of Radiology 18 (4), 570-584 (2017)

109.Z. Ghahramani, Probabilistic machine learning and artificial intelligence, Nature 521, 452-459 (2015)

110.T. Hastie, et al., Chapter 7: Model Assessment and Selection, The elements of statistical learning: data mining, inference, and prediction, 2nd Edition, Springer (2009)

111.A.P.D. Silva, Optimization approaches to supervised classification, European Journal of Operational Research 261, 772-788 (2017)

112.M.T. Hagh, et al., Fault classification and location of power transmission lines using artificial neural network, International Power Engineering Conference (IPEC), Singapore, 1109-1114 (2007)

113.M. Mousavi, K. Butler-Purry, A novel condition assessment system for underground distribution applications, IEEE Transactions on Power Systems 24 (3), 1115-1125 (2010)

114.L.H. Lee, et al., An enhanced support vector machine classification framework by using euclidean distance function for text document categorization, Applied Intelligence 37, 80-99 (2011)

115.R.A. Francis, et al., Bayesian belief networks for predicting drinking water distribution system pipe breaks, Reliability Engineering \& System Safety 130, 1-11 (2014)

116.L. Chen, et al., An ultrasonic guided wave signal processing and pattern recognition tool for studying the discontinuity axial length, Materials Evaluation 75 (5) (2017) 
117.K. Sepahvand, Stochastic finite element method for random harmonic analysis of composite plates with uncertain modal damping parameters, Journal of Sound and Vibration 400, 1-12 (2017)

118.H. Dai, et al., Nonlinear system stochastic response determination via fractional equivalent linearization and Karhunen-Lòve expansion, Communications in Nonlinear Science and Numerical Simulation 49, 145-158 (2017)

119.J. Macías-Díaz, J. Villa-Morales, A deterministic model for the distribution of the stopping time in a stochastic equation and its numerical solution, Journal of Computational and Applied Mathematics 318, 93-106 (2017) 